Department of Infectious Diseases and Infection Control, Skane University Hospital, Kioskgatan 17, 22185, Lund, Sweden

Correspondence to: U Karlsson ulf.karlsson@med.lu.se Cite this as: BMJ 2020;370:m2641 http://dx.doi.org/10.1136/bmj.m2641 Published: 07 July 2020

\section{Complete protection from covid-19 is possible for health workers}

\author{
All they need is the right protective equipment \\ Ulf Karlsson, Carl-Johan Fraenkel
}

At the start of the new coronavirus epidemic in Wuhan, healthcare workers were insufficiently protected because of lack of awareness of the emergence of a novel infectious disease. ${ }^{1}$ As recognition increased of the contagiousness of what was to be named covid-19, the strains on the medical system quickly became overwhelming, and initial shortages of personal protective equipment (PPE) continued to contribute to a substantially increased risk of infection among healthcare workers. ${ }^{2}$ Multifaceted efforts, which included increased production and reallocation of PPE, rigorous contact tracing and quarantine measures, as well as moving healthcare workers from other parts of China to the epicentre, may all have contributed to reducing the risk for healthcare workers and curbing the epidemic in Hubei province. ${ }^{3}$

In a recent $B M J$ study $^{4} \mathrm{Liu}$ and colleagues found that none of 420 doctors and nurses reallocated to frontline work at Wuhan hospitals from 24 January to 7 April 2020 contracted covid-19. ${ }^{4}$ The staff received training in proper use of PPE before their assignment and were provided with "appropriate PPE," which included protective suits, isolation gowns, gloves, face shields or goggles, hair covers, boots, and shoe covers as well as $\mathrm{N} 95$ respirators or surgical masks (both being used at the same time during aerosol generating procedures). Their main role was to care for critically ill patients with covid-19 in intensive care units, and they all participated in aerosol generating procedures. Lack of transmission of SARS-CoV-2 to healthcare workers was determined by the absence of covid-19 symptoms, repeated negative SARS-CoV-2 polymerase chain reaction test results on return from Wuhan, and serological testing.

The authors' findings are encouraging, and in line with a recent preprint study from Hefei and Wuhan that also reported that none of 426 frontline healthcare workers provided with appropriate access to PPE contracted covid-19. ${ }^{5}$ These studies underscore that adequate training and uninterrupted availability of sufficient, adequate PPE protects healthcare workers from harm, and such provision remains critical to their safety during a pandemic likely to continue for the foreseeable future.

\section{Evidence based requirements}

But what is appropriate PPE? Although it is paramount that PPE recommendations are not influenced by availability, recommending "everything always" may not improve the outcomes-infection control guidelines must be based on evidence and proper risk assessments. Transmission of SARS-CoV-2 was initially thought to be mainly airborne. Fear evoked by the death of whistle blower ophthalmologist Li Wenliang, and reports of high mortality among healthcare workers, combined with experiences from the SARS-CoV-1 epidemic, contributed to initial recommendations for maximum protection.

We now have reasonable evidence that, in accordance with WHO guidelines, droplet and contact precautions provided by a surgical face mask, eye protection, a gown, and gloves offer adequate protection in most circumstances when caring for patients with covid-19. ${ }^{67}$ Airborne transmission is considered rare, though some official guidelines have kept a cautious approach. ${ }^{89}$

The recommendation to use airborne precautions during aerosol generating procedures is universal, however, even though defining the procedures likely to create infectious aerosols is based mostly on observations from the SARS-CoV- 1 epidemic. ${ }^{10}$ Importantly, differences in transmission dynamics between SARS-CoV-2 and SARS-CoV-1 make direct extrapolation between the two unwise. While SARS-CoV-1 transmission peaked at the time of hospital admission, viral shedding of SARS-CoV-2 may peak around the time of symptom onset and even before. ${ }^{1112}$ As hospital admissions for covid-19 often occur a week or more after symptom onset (when recovery of viable virus is becoming more difficult), hospital patients, and specifically those with prolonged disease in intensive care units, may not be the most infectious individuals. ${ }^{13}{ }^{14}$ Where adequate PPE is available, the risk of transmission from patients to healthcare workers is therefore low, despite variations in the definition of what is appropriate.

Unprotected close contact with presymptomatic or mildly symptomatic patients or colleagues with unrecognised covid-19 may confer greater risk. Social distancing, a generic message in guidelines for the public, is not always achievable in a hospital. Apart from providing training in proper use of, and robust access to, appropriate PPE, implementing control measures to prevent spread of infection between healthcare workers may increase safety even further.

Current infection control guidelines seem to provide a "better safe than sorry" approach to PPE, although details may be adjusted as new evidence emerges. National authorities must make sure that durable supplies of PPE are available so that healthcare workers can abide by the guidelines. The international community must focus its efforts on supporting faltering healthcare systems, to make sure that adequate PPE is available for health workers in low and middle income countries who otherwise face a particularly high risk.

Competing interests: We have read and understood BMJ policy on declaration of interests and declare the following interests: none. 
1 Lai X, Wang M, Qin C, etal. Coronavirus disease 2019 (COVID-2019) infection among health care workers and implications for prevention measures in a tertiary hospital in Wuhan, China. JAMA Netw Open 2020;3: doi: 10.1001/jamanetworkopen.2020.9666 pmid: 32437575

2 Pan A, Liu L, Wang C, etal. Association of public health interventions with the epidemiology of the covid-19 outbreak in Wuhan. JAMA 2020;323:1-9.

doi: 10.1001/jama.2020.6130 pmid: 32275295

3 WHO. Report of the WHO-China Joint Mission on Coronavirus Disease 2019 (COVID-19). 16-24 Feb 2020. https://www.who.int/docs/default-source/coronaviruse/who-china-joint-mission-oncovid-19-final-report.pdf

4 Liu M, Cheng SZ, Xu KW, etal. Use of personal protective equipment against coronavirus disease 2019 by healthcare professionals in Wuhan, China: cross sectional study. BMJ2020;369:m2195. doi: 10.1136/bmi.m2195 pmid: 32522737

5 Wang W, Min Y-Z, Yang C-M, et al. Association of personal protective equipment use with successful protection against covid-19 infection among health care workers. medRxiv 2020.04.24.20070169. [Preprint.] doi: 10.1101/2020.04.24.20070169.

6 Chu DK, AKl EA, Duda S, Solo K, Yaacoub S, Schünemann HJCOVID-19 Systematic Urgent Review Group Effort (SURGE) study authors. Physical distancing, face masks, and eye protection to prevent person-to-person transmission of SARS-CoV-2 and COVID-19: a systematic review and meta-analysis. Lancet2020;395:1973-87. doi: 10.1016/S0140-6736(20)31142-9 pmid: 32497510

7 WHO. Clinical management of severe acute respiratory infection (SARI) when COVID-19 disease is suspected. Interim guidance 19 Mar 2020.

8 US Centers for Disease Prevention and Control. Interim infection prevention and control recommendations for healthcare personnel during the coronavirus disease 2019 (covid-19) pandemic. 22 May 2020. https://www.cdc.gov/coronavirus/2019-ncov/hcp/infection-controlrecommendations.html.

9 European Centre for Disease Prevention and Control. Infection prevention and control for COVID-19 in healthcare settings-third update. 13 May 2020. https://www.ecdc.europa.eu/en/publicationsdata/infection-prevention-and-control-and-preparedness-covid-19-healthcare-settings

10 Tran K, Cimon K, Severn M, Pessoa-Silva CL, Conly J. Aerosol generating procedures and risk of transmission of acute respiratory infections to healthcare workers: a systematic review. PLOS One 2012;7. doi: 10.1371/journal.pone.0035797 pmid: 22563403

11 He X, Lau EHY, Wu P, etal. Temporal dynamics in viral shedding and transmissibility of COVID-19. Nat Med 2020;26:672-5. doi: 10.1038/s41591-020-0869-5 pmid: 32296168

12 Cheng H-Y, Jian S-W, Liu D-P, et al. High transmissibility of COVID-19 near symptom onset. medRxiv 2020.03.18.20034561. [Preprint.] 2020. doi: 10.1101/2020.03.18.20034561

13 Wölfel R, Corman VM, Guggemos W, etal. Virological assessment of hospitalized patients with COVID-2019. Nature 2020;581:465-9. doi: 10.1038/s41586-020-2196-x pmid: 32235945

14 van Kampen JA, van de Vijver DAMC, Fraaii PLA, et al. Shedding of infectious virus in hospitalized patients with coronavirus disease-2019 (COVID-19): duration and key determinants. medRxiv 2020.06.08.20125310. [Preprint.]

2020. doi: https://doi.org/10.1101/2020.06.08.20125310

This article is made freely available for use in accordance with BMJ's website terms and conditions for the duration of the covid-19 pandemic or until otherwise determined by BMJ. You may use, download and print the article for any lawful, non-commercial purpose (including text and data mining) provided that all copyright notices and trade marks are retained. 